The Journal of Public Space

2018 | Vol. 3 n. I

\title{
VIEWPOINT
}

\section{Application to Occupy}

\section{Grace Leone}

RMIT University, Australia

grace.leone@rmit.edu.au

'A city finds itself 'Under Construction'... a permanent state of affairs.'

(Koolhaas \& Foster 2013: 48)

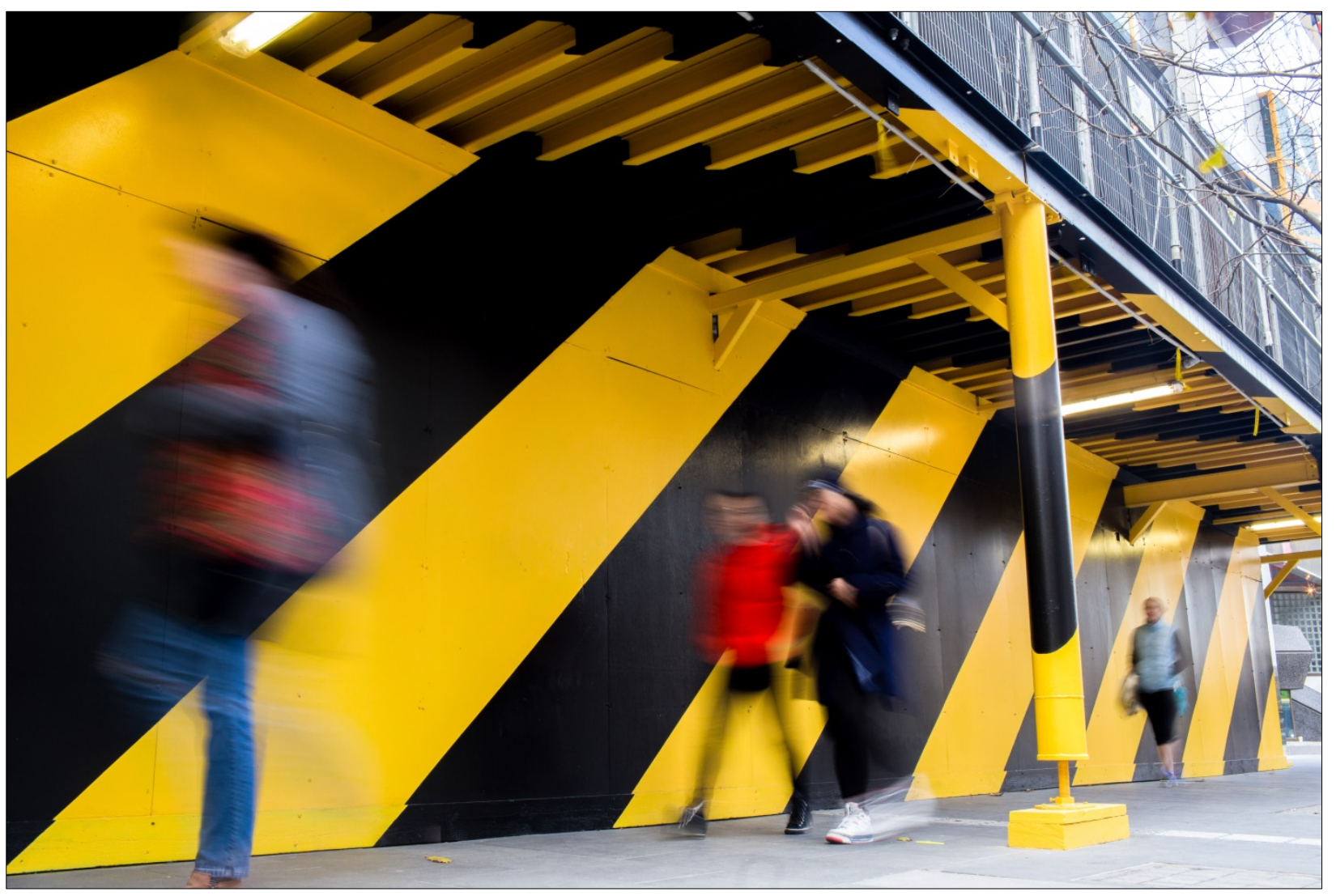

Fig. I. Gantry Section D, RMIT Swanston St, Melbourne 20 I 6-20 I 7. Artwork: Grace Leone.

Photo Credit: Nura Sheidaee

Urban Animators: Living Laboratory (UA:LL) was a public art research project that actively engaged with the RMIT University New Academic Street capital works project, undertaken at the Melbourne city campus from 20I5-20I7. The construction site and the 
surrounding campus were envisaged as a living laboratory encouraging research that engaged with the internal infrastructure, process and community of RMIT University. As curator of the UA:LL public art program I created a framework that encouraged collaboration, provocation, solidarity and exchange amongst RMIT University students, staff and alumni. This was achieved through the process of open expression of interests, learning and teaching, invited artists and industry research partnerships all resulting in public artworks embedded in the construction zone. The artistic installations included public artworks on construction hoardings and projections within the constriction zone that positively activated the site condition and helped mitigate the disruption occurring on the campus.

As a curator, artist and designer I proposed a spatial curatorial proposition to the city via a public art installation titled 'Gantry Section D' as part of the UA:LL program. 'Gantry Section D' was the result of an intensive period of practice based investigation into the condition created when a city is undergoing transformation. During the process of construction, property developers gain permission to occupy the public space of footpaths and roads to accommodate processes and equipment directly related to building construction. This council permission is provided through a formal permit application and payment of associated costs. The calculation of the permit is typically calculated by multiplying the number of weeks of occupation, by the total area occupied, by the weekly occupancy rate. Essentially the public footpaths and roads become available for rent during construction processes resulting in a particular spatial condition littered with the construction hoarding and gantries.

My fieldwork investigated and documented this spatial condition using photography and performance within cities and suburbs in Melbourne and Shanghai taking note of the materials, colours, textures, layers, pedestrian activity and compositions. The presentation of the photographic documentation Photographic Matrix (Figure I) is an extension of the fieldwork as the intentional gridded matrix of the images is an attempt to highlight the imposed perception of order versus the chaos in the experienced space. My production of a public performance piece, 'Shanghai Scaffolding' (Shanghai China, 2015) investigated the construction scaffolding occupation of the footpath, the pedestrian and the hazard tape. The performance and the physical composition of the elements highlighted the tension between the pedestrian and the public space occupied by construction gantries.

The fieldwork (Figure 2-5) informed the creation of 'Gantry Section D' a public art installation named after the notation used on architectural drawings that communicated the hoarding layout to builders. At the site of this installation the construction hoarding was the first piece of temporary architecture that was erected; delineating the construction zone from the public space. The construction gantry was then erected creating a space which corralled the public along the street. The steel columns and beams of the gantry supported an overhead platform which created a zone cantilevering over the footpath for builders to occupy with construction equipment. The footpath became formally occupied by the architecture of the gantry.

'Gantry Section D' expressed the architecture of the temporary hoarding and gantry occupying the public space by employing the iconography of the yellow and black hazard strip. The intention was to transform the occupied public space and create a spatial environment that visually privileged the pedestrian. The use of yellow and black stripes referenced the Australian Standards ASI 318 which states 'yellow shall be the basic or 
background colour, used alone or in conjunction with black for marking the following places where caution should be exercised and where cautionary notices of a general nature should be displayed.'

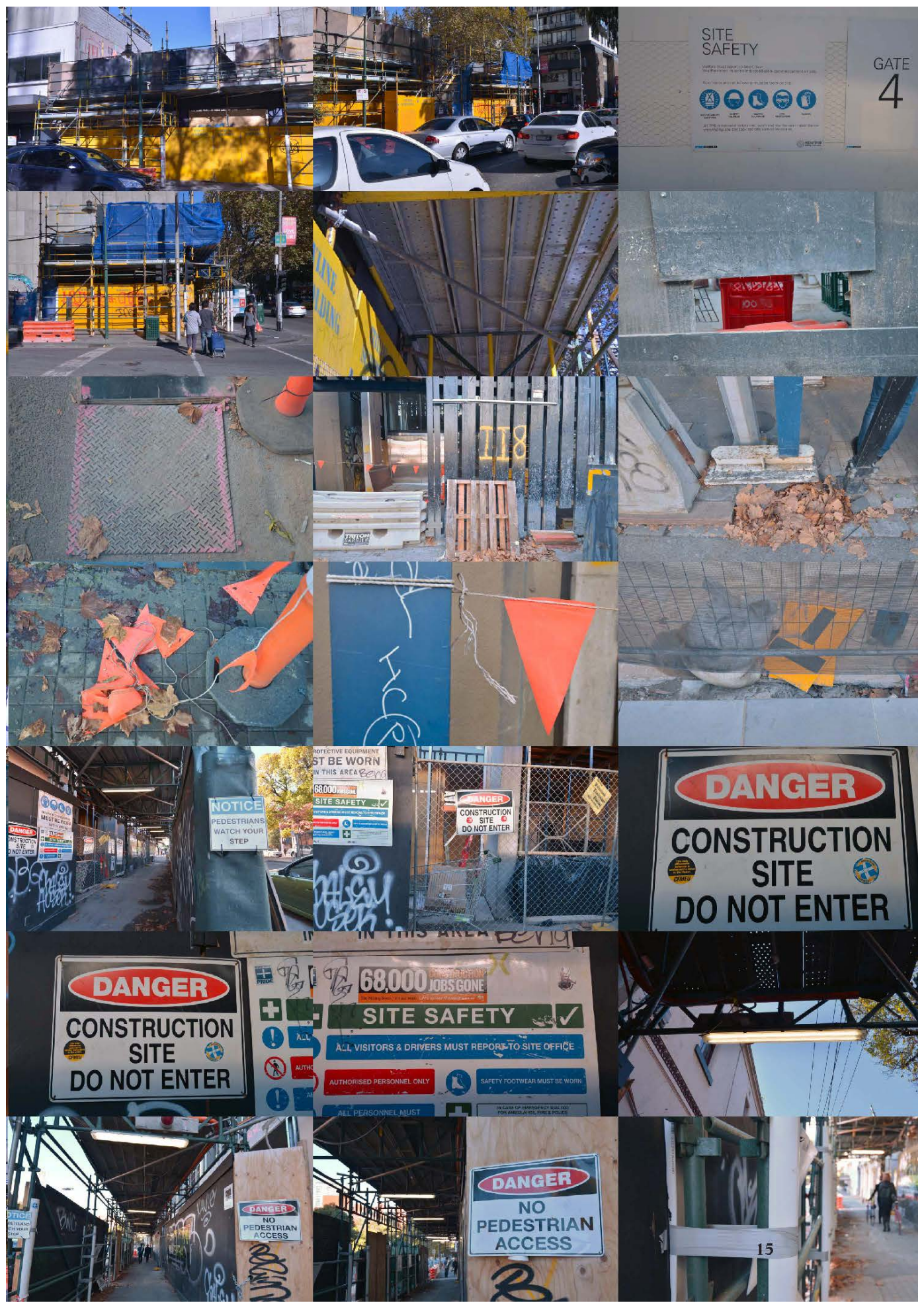

Fig. 2. Photographic Matrix. Artwork: Grace Leone. Photo Credit: Grace Leone. 

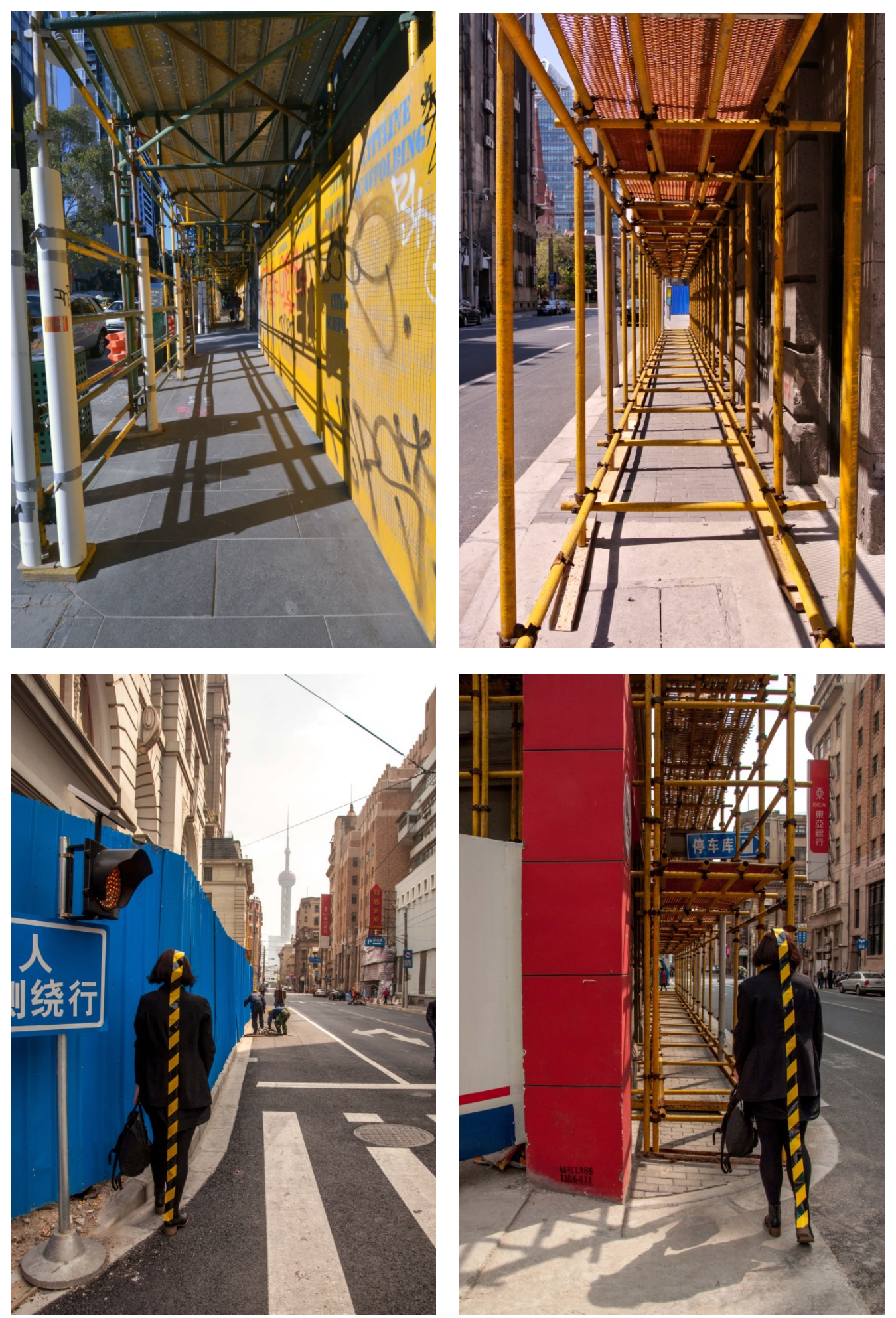

From top, clockwise. Fig. 3. Construction Gantry, Melbourne, 20I5. Artwork: Grace Leone. Photo Credit: Grace Leone. Fig. 4. Construction Gantry, Shanghai, 2015. Artwork: Grace Leone. Photo Credit: Grace Leone.

Fig. 5. Shanghai Scaffolding Intervention I, Shanghai, China, 2015. Artwork: Grace Leone. Photo Credit: Grace Leone. Performer: C. McCracken.

Fig. 6. Shanghai Scaffolding Intervention 2, Shanghai, China, 2015. Artwork: Grace Leone. Photo Credit: Grace Leone. Performer: C. McCracken

106 | The Journal of Public Space, 3(I), 2018 | ISSN 2206-9658

City Space Architecture / Queensland University of Technology / UN-Habitat 

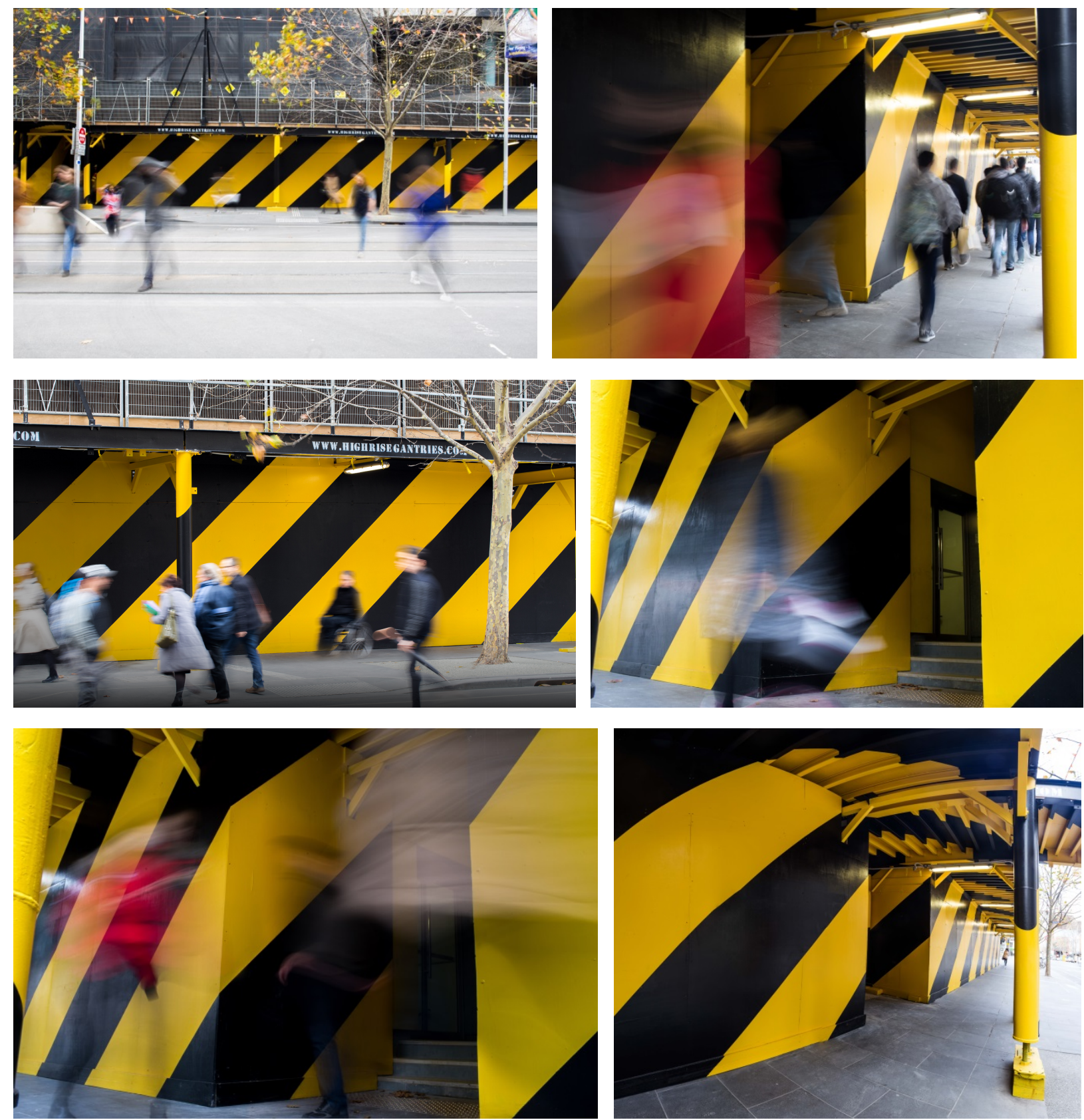

Fig. 6-I I. Gantry Section D, RMIT Swanston St, Melbourne 20 I6-20 I 7. Artwork: Grace Leone. Photo Credit: Nura Sheidaee.

The iconography of the yellow and black stripe was intentionally scaled to human proportions creating a backdrop to the activities of the pedestrians and bringing to the forefront the effects of the gantry structure occupation on public space. The painted application of the yellow and black stripe extended over the wall of the hoarding and up to the underside of the platform overhead. The columns supporting the platform also received an application of the stripe, the composition ensuring that if viewed from across the road the stripes aligned with the stripes on the hoarding wall. The intention was to also acknowledge the architecture of the bluestone pavement as part of the spatial 
condition with an application of painted yellow and black stripes. However council permits did not look favourably on the application of a painted graphic onto permanent structures in public space.

'Gantry Section D' became a stage for the everyday activities of pedestrians in public space occupied by construction hoarding and gantries. The application of the yellow and black hazard stripe on the spatial condition returned the focus back onto the pedestrian by placing them centre stage. 'Gantry Section D' questioned the public environment created when property developers are granted the permission to occupy public space during a city under construction.

'The stripe is not disorder; it is sign of disorder and a means of restoring order. The stripe is not exclusion; it is a mark of exclusion and an attempt at re integration.'

(Pastoureau, 2003: 90).

\section{References}

Koolhaas, R., Foster, H. (2013), Junkspace with Running Room, Notting Hill, Editions London. ASI 318 Australian Standards Industrial Safety Colour Code, 1985. Section 3. Application and examples of yellow.

Pastoureau, M. (2003). The Devil's Cloth: A History of Stripes, Wastington Square Press.

\section{To cite this article:}

Leone, G. (2018). Application to Occupy. The Journal of Public Space, 3(I), 103-108. DOI: I0.5204/jps.v3il.32I

This article has been accepted for publication in The Journal of Public Space. Please see the Editorial Policies under the 'About' section of the journal website for further information. 